\title{
Atuação do Psicólogo em Organizações não Governamentais na Área da Educação
}

\author{
The Work of Psychologists in Non-governmental \\ Organizations in the Educational Field
}

El Trabajo de los Psicólogos en Organizaciones no Gubernamentales en Educación

Luciana Dadico \&

Marilene Proença

Rebello de Souza

Universidade de São Paulo

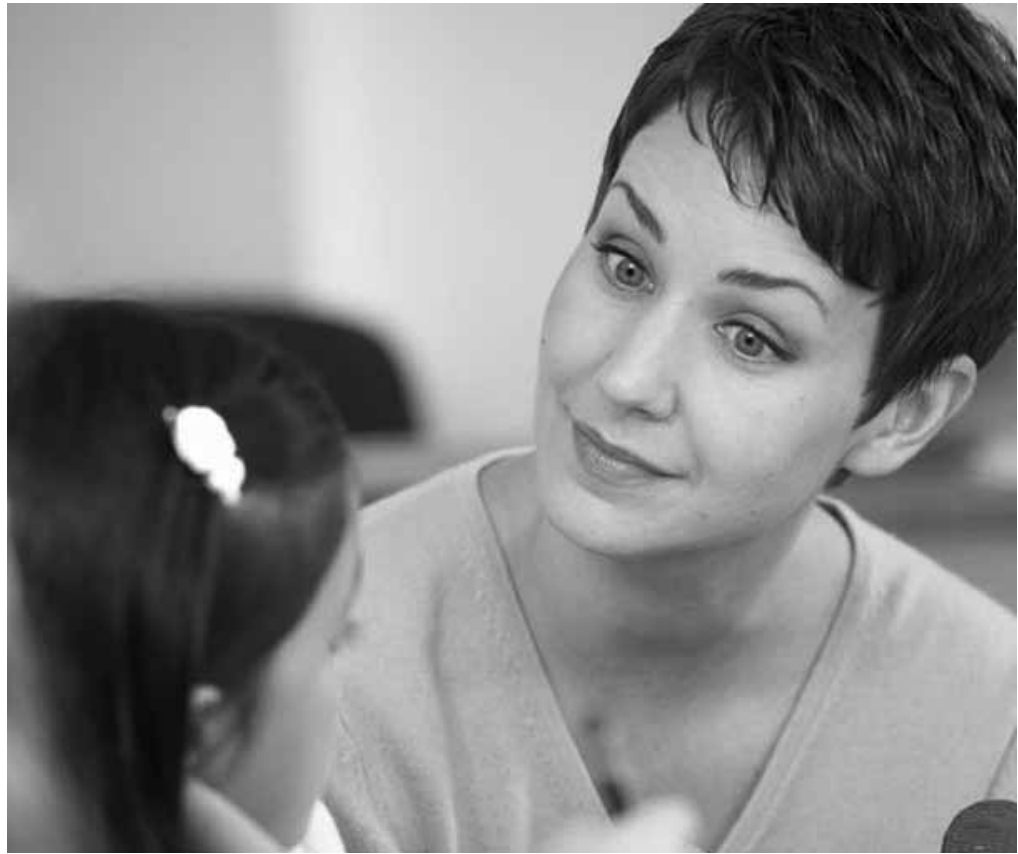


Resumo: Este trabalho se faz presente em um contexto de transformações nos discursos e práticas educacionais que acompanham a globalização e a crise econômica dos Estados nacionais, atribuindo a novos personagens, as organizações não governamentais, a tarefa de promover melhoria no atendimento escolar. O objetivo principal da presente pesquisa é conhecer o trabalho de psicólogos que atuam em organizações não governamentais no campo educacional, com ênfase nas especificidades desse trabalho bem como nas principais questões relacionadas à atuação dos profissionais. Assim, constituíram informações importantes para a pesquisa as características das organizações não governamentais que afirmam ter como missão atuar na área educacional, as características do trabalho realizado pelos psicólogos que atuam nessas instituições e as questões que os psicólogos destacaram como constituintes do trabalho realizado na área da educação. A realização deste estudo baseou-se principalmente nos conceitos de sociedade civil, de Gramsci, e nos princípios que norteiam uma educação libertadora e uma psicologia comprometida com o oprimido. Espera-se, assim, contribuir para a reflexão que vem se operando no terreno em que confluem a atuação das ONGs, a educação pública e a prática profissional em Psicologia no País, fornecendo subsídios, de modo mais direto, aos estudiosos e profissionais que atuam nessas áreas.

Palavras-chave: Atuação do psicólogo. Organizações não governamentais. Educação. Educação libertadora

Abstract: This paper is presented in a context of transformation in the discourses and educational practices as they try to keep up with globalization and the economic crisis in national states, assigning to new agents, the nongovernmental organizations, the task of enhancing school service. The main objective of the research is to study the work of psychologists in non-governmental organizations in the educational field, focusing the specificity of this work as well as the principal issues related to their work in this area. Therefore, important information for the research was found in the characteristics of the non-governmental organizations that state their mission as the work in the educational area, the characteristics of the work carried out by the psychologists who work in these institutions and the issues pointed out by the psychologists as part of the work in the educational field. The present work was based mainly on Gramsci's concept of civil society and on the principles that guide a liberating education and a psychology which is committed to the oppressed. As a result of this task, we expect to contribute to the discussion that has been taking place on the ground where the work of NGOs, public education and the professional psychological practice meet in Brazil, providing resources to scholars and professionals who work in this field.

Keywords: Psychologist practice. Non-governmental organizations. Education. Liberating education.

Resumen: Este trabajo se hace presente en un contexto de transformaciones en los discursos y prácticas educacionales que acompañan la globalización y la crisis económica de los Estados nacionales, atribuyendo a nuevos personajes, las organizaciones no gubernamentales, la tarea de promover mejora en el servicio escolar. El objetivo principal de la presente pesquisa es conocer el trabajo de psicólogos que actúan en organizaciones no gubernamentales en el campo educacional, con énfasis en las especificidades de ese trabajo bien como en las principales cuestiones relacionadas a la actuación de los profesionales. Así, constituyeron informaciones importantes para la pesquisa de las características de las organizaciones no gubernamentales que afirman tener como misión actuar en el área educacional, las características del trabajo realizado por los psicólogos que actúan en esas instituciones y las cuestiones que los psicólogos destacaron como constituyentes del trabajo realizado en el área de la educación. La realización de este estudio se basó principalmente en los conceptos de sociedad civil, de Gramsci, y en los principios que nortean una educación libertadora y una psicología comprometida con el oprimido. Se espera, así, contribuir con la ponderación que viene siendo operada en el terreno en el que confluyen la actuación de las ONGs, la educación pública y la práctica profesional en Psicología en el País, suministrando subsidios, de modo más directo, a los estudiosos y profesionales que actúan en esas áreas.

Palabras clave: Actuación del psicólogo. Organizaciones no gubernamentales. Educación. Educación libertadora.

As chamadas novas configurações do mundo do trabalho inserem formas de organização e de remuneração na atuação profissional em diversos setores sociais. Diante das políticas neoliberais de enxugamento do aparato estatal e das demandas sociais postas pelos setores mais empobrecidos da população, uma das alternativas encontradas pela sociedade civil e pelos setores organizados centra-se na constituição das denominadas organizações não governamentais e suas derivações. Tal fato ocasionou um importante aumento na quantidade de organizações não governamentais em atuação no Brasil, e os discursos tecidos em torno de tal fenômeno receberam muitos contornos e significações no campo das políticas públicas. Hoje os termos associados àquele que se convencionou chamar o terceiro setor ou setor não-governamental compõem nosso vocabulário corrente, com 
${ }^{1} \mathrm{O}$ modo como

a queixa escolar comparece na formação do psicólogo pode ser tomada como um dos mais evidentes casos em que uma visão distorcida e tecnicista de

Psicologia acaba construída e vigorando nos cursos de Psicologia e nas clínicasescola brasileiras (Souza, 2000). O enfrentamento dessa questão diz respeito ao próprio compromisso da Psicologia na manutenção/ superação da situação educacional do País. palavras como ONGs, responsabilidade social, projetos sociais, programas, OSCIP, sociedade civil, filantropia empresarial, sustentabilidade social, etc, sobretudo para aqueles que de algum modo compartilham interesses e/ou preocupações na ação social, termos que, deslocados de seu uso original, contudo, não raro acabam manipulados em um contexto em que a confusão de sentidos parece proposital (Arantes, 2000).

Dados do Cadastro Central de Empresas do Instituto Brasileiro de Geografia e Estatística IBGE (2005) dão conta, em seu levantamento mais recente, da existência de 601.611 entidades ditas sem fins lucrativos em atuação no País. Se excluirmos desses dados figuras jurídicas tais como caixas de escola, cartórios, partidos políticos, entidades do Sistema $S$ (Sesc, Senac, etc), condomínios e sindicatos, teremos por base 338.162 organizações, dentre as quais 19.940 atuam diretamente na área educacional (esse número sobe para 79.931 se extensivo ao conjunto das organizações). Tais entidades empregam mais de 1 milhão e 700 mil pessoas, um número cerca de três vezes superior ao de servidores federais na ativa. Do total de empregados nessas entidades, 29\% atuam na área educacional. Diante de um quadro de privatização dos serviços, com consequente encolhimento da atuação direta do Estado nas áreas sociais, esses números tendem ao crescimento. Dentro das organizações que atuam exclusivamente na área da assistência social (IBGE, 2007), o que corresponde a 33.076 entidades ou a $10,2 \%$ do total, encontramos o número absoluto de 5.428 psicólogos em atuação.

No interior desse novo quadro das relações de trabalho, observamos que os psicólogos vêm sendo sistematicamente contratados para atuar no chamado terceiro setor. O Conselho Federal de Psicologia - CFP destaca que, nas áreas passíveis de serem qualificadas como pertencentes a um setor não governamental, encontrávamos trabalhando, em 2001, 2,7\% dos psicólogos do País (CFP, 2003). Do total, 9,7\% dos psicólogos atuavam na área educacional no mesmo ano (o número sobre para 18,15\% no Estado de São Paulo). Em 2000, eram 6,9\% atuando em instituições; em 2004, 11\% na área de políticas públicas.

Uma pesquisa recente ${ }^{1}$, que buscou atualizar as informações do Conselho Federal sobre a ocupação do psicólogo brasileiro, verificou, no período de junho de 2006 a abril de 2007, dentre os inscritos nos Conselhos Regionais de Psicologia do País que responderam voluntariamente a um questionário disponível na internet, alguns dados interessantes. Para os psicólogos que informaram atuar no terceiro setor, a forma prioritária de acesso ao cargo era o concurso ou o processo seletivo (49,5\%), seguido daqueles com contrato como autônomo (29\%) ou voluntário (35\%). A carga horária de trabalho predominante era de até 20 horas semanais $(71,5 \%)$. Desses profissionais, 58\% exerciam suas atividades majoritariamente em grupos multiprofissionais, sendo que $77 \%$ se declaravam satisfeitos por trabalhar no terceiro setor, e 70\% percebiam oportunidades de crescimento no mesmo (Macedo, 2008). Esses dados condizem com os resultados obtidos pela pesquisa que relatamos e discutimos a seguir.

Quando pensamos sob o ponto de vista das políticas educacionais, notamos que a educação se faz uma das áreas preferenciais de atuação das organizações não governamentais, e que estas apresentam um modus operandi bastante característico, com repercussões consideráveis principalmente junto à escola pública. $\mathrm{O}$ desconhecimento a respeito da ação das organizações não governamentais no País, contudo, ainda é grande, bem como é grande a ausência de reflexões mais aprofundadas 
sobre o assunto que encontrem vias de escape ao discurso hegemônico. Para os psicólogos voltados para a área social, que desejam atuar ou já atuam nessas organizações, tais reflexões se fazem prementes.

Em vista da importância do tema, este artigo pretende apresentar os resultados de uma pesquisa realizada junto a psicólogos atuantes em organizações não governamentais na área da educação, com o objetivo de conhecer o trabalho desses profissionais, identificar especificidades de seu trabalho e realizar uma análise das principais questões por eles levantadas ao exercer sua atuação profissional.

\section{Método}

A pesquisa, realizada entre os anos 2000 e 2003, contou com a participação de onze psicólogos, atuantes em cinco organizações não governamentais sediadas no Município de São Paulo, sendo três delas de alcance nacional. Essas ONGs tinham por característica comum se autodeclararem atuantes na área da educação, e diferenciavam-se entre si na medida em que apresentavam vinculações institucionais diretas (com empresas, governo, outras entidades, etc) variadas. As entrevistas, como fonte principal de informação, foram realizadas com a ajuda de um gravador, conforme as sugestões de Maria Isaura Pereira de Queiróz (1983), e transcritas pela pesquisadora.

A análise qualitativa dos dados da entrevista buscou preservar, da melhor maneira possível, a relevância e os significados dados pelos entrevistados às suas próprias falas (Oliveira, 1998) bem como tomar em consideração os diferentes contextos nos quais essas falas ocorreram, em atenção à validade das informações produzidas
(Rockwell, 1987). Procurou-se, ao longo das entrevistas, compreender a natureza do trabalho realizado pelos psicólogos nas organizações não governamentais. Nortearam essa busca as seguintes questões: qual a trajetória profissional dos psicólogos e que razões motivaram suas escolhas? Que tarefas o psicólogo realiza na organização? Quais as características dessa atuação? Como se dão as relações profissionais estabelecidas na ONG? Quais as consequências desse trabalho para o profissional? Como o psicólogo se relaciona com o trabalho que desenvolve?

O sigilo dos entrevistados e das organizações envolvidas será preservado omitindo-se o nome dos psicólogos e das organizações envolvidas no estudo, identificadas como ONG A, ONG B, e assim por diante.

A partir dos depoimentos e das análises feitas com base nos objetivos da pesquisa, pudemos destacar as seguintes unidades de análise: a) trajetória profissional dos psicólogos que atuam em ONGs; b) funções exercidas e trabalhos realizados por psicólogos; c) contratos de trabalho nas organizações não governamentais e d) relações de trabalho e militância. Cada um desses aspectos será detalhado a seguir.

\section{Trajetória profissional dos psicólogos em atuação nas ONGs}

Os psicólogos que participaram da pesquisa trabalhavam em suas respectivas organizações há períodos variados, de 1 a 14 anos. Aqueles que possuíam maior tempo de casa eram, também, os de maior nível hierárquico no interior da organização, acompanhando a organização desde seus primeiros anos. Os psicólogos atuavam em funções diversas no momento da entrevista, contratados 
como assistentes técnicos, pesquisadores ou coordenadores de áreas ou projetos específicos. Quatro deles ocupavam funções relacionadas à direção na organização em que atuavam: em cargos de gerência ou coordenação geral. Uma das psicólogas atuava simultaneamente em duas organizações, ocupando postos diferentes em cada uma delas: em uma das organizações, atuava na direção, e, em outra, como contratada.

Os psicólogos descreveram diversos aspectos de sua formação, ressaltando partes do currículo acadêmico e de cursos específicos que influenciaram de algum modo sua trajetória profissional. A maioria relatou possuir em algum momento ou ainda manter uma relação mais próxima com a psicanálise e/ou com a área escolar, por meio de estágios, especializações, mestrado ou mesmo como opção de estudo. Dois psicólogos haviam realizado alguma especialização e três haviam feito ou ainda faziam pós-graduação em Psicologia, dois na área educacional e uma na área clínica.

A maior parte dos psicólogos entrevistados teve sua primeira experiência de trabalho em ONGs na própria organização em que estava atuando, o que representava, em alguns casos, vários anos de trabalho. Em apenas duas situações os entrevistados haviam trabalhado em mais de uma ONG, anteriormente. Nesses casos, foram citadas as áreas ambiental, assistencial, de educação infantil, direitos humanos, direitos da criança e do adolescente, atendimento a meninos de rua e cultura e educação de jovens. Apenas uma das pessoas entrevistadas possuía relação com movimentos sociais antes de ingressar na organização. Quatro possuíam experiência em pesquisa, em projetos de iniciação científica ou pós-graduação. Em dois casos, as pesquisas relacionavam-se a uma organização não governamental. Em um deles, o trabalho em pesquisa permaneceria como foco de atuação também na ONG em que o entrevistado se inseriu.

Exceção feita aos psicólogos que trabalhavam na ONG E, todos os demais entrevistados contaram ter chegado à ONG por um interesse ou por experiência profissional anterior na área da educação. Em parte desses casos, tratava-se de um interesse difuso, que orientou a prática profissional, em primeiro lugar, para a área educacional, depois - e de forma ocasional - para o trabalho em ONGs. Como relata um dos entrevistados:

Eu me formei em 92 e já trabalhava numa fundação, numa autarquia estadual, com alfabetização de jovens e adultos. E, de lá para cá, esses dez anos de carreira profissional que eu tenho foram dedicados à educação, seja de jovens e adultos, ou educação ambiental, ou educação fundamental.... Então, acho que a minha carreira é muito curiosa por causa disso, ela foi sendo construída, não foi intencional, sabe, 'vou ser um profissional do terceiro setor', eu nem sabia o que era isso em 92.

Duas psicólogas, apenas, disseram ter deliberadamente buscado o trabalho em ONGs, por razões diferentes. Em um dos casos, porque a psicóloga via na organização não governamental uma alternativa ao trabalho em escolas particulares, voltadas para o atendimento de crianças da elite; em outro caso, por vislumbrar na ONG uma possibilidade de desenvolver um trabalho próprio de pesquisa, que desejava fazer distante da Academia e mais próximo de uma possível intervenção prática. Nesse caso, vemos repercutir mais diretamente junto aos profissionais e futuros profissionais os discursos tecidos em torno das ONGs. 
Todos os psicólogos que declararam ter optado deliberadamente pela educação como área de atuação profissional vislumbravam alcançar realizações coletivas a partir desse trabalho. O sentido social ou político do trabalho assumia, contudo, diferentes matizes, intimamente relacionados às concepções de educação, aos diagnósticos tecidos em relação aos problemas da escola pública e à visão do público atendido por meio da ONG.

Algumas das finalidades atribuídas à educação que surgiram em uma ou mais entrevistas podem ser elencadas da seguinte maneira: a) como forma de melhorar o povo, tornando-o capaz de melhor discernimento; b) associada à ascensão profissional do pobre; c) como meio de reduzir as desigualdades econômicas, sociais, culturais e raciais; d) como parte das políticas públicas de saúde e e) como direito, cujo acesso é necessário garantir. A importância desses sentidos, em última instância, surgia na medida em que correspondia ao projeto político da própria ONG: em alguns casos, entrelaçavam-se à incongruência no emprego de termos como turbinar a aula, ou acelerar a aprendizagem, que destituem a educação de seus aspectos mais humanos para aproximá-la do campo da técnica, posta desde cedo como quesito de competição na vida dos alunos. Por outro lado, na medida em que, em muitos casos, a responsabilidade pelos problemas educacionais enfrentados na escola pública recai sobre os próprios beneficiários do trabalho da ONG, esta surge para suprir a própria demanda que diagnostica. Em um dos casos mais evidentes, em que a venda do trabalho técnico se seguia à localização da demanda, os professores eram apontados como os principais responsáveis pelo fracasso escolar, enquanto o trabalho da ONG consistia justamente em oferecer formação para esses professores, em larga escala (projetos vendidos, sobretudo às secretarias de Estado da Educação), por meio de oficinas, publicação de materiais didáticos e instituição de prêmios educacionais.

Assim é que, no relato de uma das psicólogas, se a educação possui o significado de uma atuação abrangente, capaz de atingir um número maior de beneficiários do que o trabalho clínico, por outro, constitui instrumento de melhoria do povo, que não sabe pensar direito:

Eu já tinha um interesse na área da educação desde o início da faculdade, porque é uma coisa que sempre veio na minha cabeça: do jeito que está o País hoje em dia, a educação é prioridade. Quanto mais pessoas virem a trabalhar na área da educação, melhor, porque só com educação você pode melhorar alguma coisa, é básico. A economia pode melhorar, mas se a educação não melhorar, o povo não vai melhorar. Ter mais dinheiro para comprar e não ter ideia na cabeça, não ter discernimento, não saber pensar direito... Eu sempre pensei assim, educação é prioridade. Foi por isso, também, que eu nunca pensei em fazer clínica, sempre quis ir para a área da educação. Pode ser um preconceito meu, mas eu achava um pouco chatinho ficar dentro de um consultório tratando do problema de uma pessoa sendo que tem uma multidão que a gente pode ajudar com a educação.

No relato de outro psicólogo, o trabalho educacional envolve uma motivação política ao voltar-se para o público da periferia:

Quando eu entrei na graduação em Psicologia, também comecei a dar aulas como professor. A princípio, por questões de sobrevivência, eu dava aulas à noite, a faculdade era o dia inteiro. Mas depois, acho que fui tomando gosto pela coisa, por educação e por educação de adolescentes, basicamente, 
pelo desafio que isso representava, e por adolescentes de periferia, também isso, porque depois eu dei aulas para adolescentes não de periferia e não curti nada, não achei nada interessante. Faltou uma motivação política, você perde a motivação política, eu acho. E acho que isso me influenciou bastante também para escolher a área da Psicologia para a qual eu iria me dirigir.

O trabalho aparece ainda como possibilidade de volta às raízes. Na fala de uma das psicólogas, o trabalho realizado pela ONG representa um retorno, uma volta do aprendizado alcançado do outro lado do rio Tietê à sua comunidade de origem e a possibilidade de suprir a carência de meios encontrada no bairro da periferia que já habitara:

Meus pais sempre atuaram em movimentos sociais, movimentos populares nas comunidades, e ajudaram a construir o bairro em que eles moram.... Foi na faculdade que eu fui entender como a gente já agia com o método de Paulo Freire mesmo sem saber, conversando com as pessoas. Eu trabalhei durante bastante tempo na comunidade, trabalhei um tempo na escola da comunidade, na escola pública.... Aí, fui fazer faculdade e me distanciei dos trabalhos de lá.... Tem um divisor de águas da periferia pra cidade, você atravessa o rio Tietê, é outro mundo. Daí, eu fui descobrindo um monte de outras coisas que lá não tinha, atividades culturais, não tem nada lá.... Na época em que eu trabalhava na rua com os meninos, já era um desejo muito grande meu, até porque era um bairro muito distante que eu morava, o desejo de pensar um trabalho de qualidade, um espaço de qualidade e cultura lá, na comunidade.

A partir de projetos políticos, de ideais e experiências diversas, os psicólogos vão revelando o sentido da ação que constroem nas organizações não governamentais às quais se vinculam.

\section{Funções exercidas e trabalhos realizados por psicólogos}

Todas as atividades educacionais implementadas pelas organizações presentes neste estudo contavam com a participação dos psicólogos em algum momento de sua realização. Em quatro das cinco organizações pesquisadas, os psicólogos não se diferenciavam dos profissionais de outras áreas ao assumir funções dentro da organização. Assim como outros profissionais, integravam equipes multidisciplinares ou ocupavam postos abertos, de modo genérico, aos profissionais da área de humanas. Em apenas uma das organizações, os psicólogos encontravam atribuições de cargos específicos para a formação em Psicologia, não por acaso, uma organização fundada por um grupo de psicólogos. Nesse caso, os psicólogos assumiam os postos de coordenação e/ou eram encarregados de participar de atividades que envolviam algum tipo de intervenção institucional, educacional ou terapêutica. $\mathrm{Na}$ maior parte das ONGs, porém, os psicólogos assumiam tarefas que, com o passar do tempo, passavam a compor um perfil do profissional no interior da organização. Assim, o psicólogo vai desempenhar, ao longo de sua carreira, funções para as quais se entende que ele possua pontos fortes, experiência, interesse e/ou habilidade.

Em três das ONGs estudadas, os psicólogos contratados eram encarregados, no momento da entrevista, de projetos específicos, que desenvolviam, coordenavam e pelos quais respondiam perante a organização. Esses projetos envolviam a aplicação de novas tecnologias em educação, a realização de pesquisas, a realização de atividades de arte e cultura, intervenções na escola, produção de eventos e elaboração de 
materiais educativos. Em outras duas ONGs, por outro lado, os psicólogos, contratados, tinham cargos fixos e funções pré-definidas dentro da organização, como assessoria, acompanhamento de projetos externos e coordenação das atividades da ONG em determinado nível de atuação.

Três psicólogas relataram ter ingressado na organização na qualidade de estagiárias ou trainees, ainda durante o curso de graduação ou logo após formadas. Nesses casos, as diferenças relacionadas à concepção de estágio presente na ONG trouxe consequências para as tarefas que realizavam à época de seu ingresso. Se, na ONG A, as tarefas de estágio, de natureza burocrática, envolviam atividades como tirar fotocópias e organizar materiais, que iam sendo abandonadas à medida que a psicóloga conseguia participar de tarefas mais diretamente relacionadas aos aspectos técnicos educacionais da ONG; na ONG B, de modo inverso, o estágio acontecia em um programa de avaliação de projetos externos, deixado no momento em que a psicóloga se candidata a uma vaga interna, passando a atuar em outra área da organização; nesse caso, é a partir desse momento que ela começa a realizar mais tarefas de caráter burocrático, relacionadas ao trabalho de assessoria que passa a exercer. Na ONG E, o estágio irá compor a própria política de formação de profissionais implementada pela ONG; assim, os trabalhos realizados no período de estágio já envolvem atividades de pesquisa que posteriormente a psicóloga irá desempenhar como profissional.

A realização de trabalhos burocráticos figura como queixa comum nas ONGs de maior porte. Em geral, estavam associados ao desenvolvimento de projetos de grande alcance, à estrutura da organização (dividida em várias áreas e departamentos), ao relacionamento com agentes institucionais externos e à prestação de contas por financiamentos recebidos.

Atividade comum à grande parte dos psicólogos era a participação em oficinas educativas. As oficinas educativas se fazem presentes em vários momentos do trabalho das ONGs pesquisadas, como modo emblemático da atuação das ONGs em educação (Dadico, 2003). A elaboração de projetos figura como a segunda maior atividade desenvolvida por psicólogos nas organizações estudadas, presente - em diferentes momentos do trabalho dos psicólogos - em todas as organizações. O desenvolvimento dessa tarefa, contudo, envolvia diferentes graus de autonomia e de possibilidade de criação para o psicólogo em cada uma das ONGs: limitados, ou a partir da própria organização interna da ONG ou, principalmente, pela influência dos financiadores nos projetos implantados. Do ponto de vista financeiro, os projetos educacionais eram gestados a partir de dois movimentos: os financiadores que buscavam a organização para concretizar determinada proposta ou a ONG que elaborava um projeto e partia em busca de financiamento. No primeiro caso, os psicólogos participavam desses projetos em três momentos: na transformação da ideia proposta pelo financiador em projeto passível de concretização - tarefa restrita, em algumas ONGs, aos níveis hierárquicos superiores -; no planejamento operacional do projeto e em sua execução, que envolvia, dependendo do caso, oficinas, elaboração de materiais, participação em reuniões, intervenções na escola e/ou entidades, realização de pesquisas, produção 
de eventos e outras. No segundo caso, dois modos diferentes de elaboração de projetos foram mencionados. Em um deles, o psicólogo elaborou um projeto a partir dos valores e concepções teóricas defendidos por ele e pela organização e apresentou-o a um possível financiador, que recusou o financiamento sem maiores explicações. Em outro, os coordenadores da ONG elaboraram um projeto de grande alcance, calcado em valores consolidados na organização, e, já contando com bastante experiência no mercado, buscaram financiamento a partir de uma estratégia determinada, de pulverizar o número de financiadores e as quantias recebidas em cada financiamento, a fim de minimizar a influência dos financiadores nos rumos do projeto.

Uma atividade mencionada com frequência nas entrevistas é a elaboração de materiais de capacitação e publicações. Uma atividade não relacionada à Psicologia para a qual psicólogos de várias ONGs eram bastante solicitados era a revisão de textos, atribuída a psicólogos que mostravam capacidade para tal. Em duas organizações, psicólogos atuavam ou já haviam atuado na área de recursos humanos. Em um dos casos, duas psicólogas participavam de modo sistemático do processo de seleção profissional e de avaliação dos funcionários da organização, e uma delas, superior hierárquica, cuidava também de tarefas relacionadas ao desenvolvimento das equipes e da instituição de um modo geral. Em outra ONG, uma das psicólogas entrevistadas, que atua prioritariamente em atividades de pesquisa, relatou uma situação em que foi chamada a desenvolver um processo de seleção ao lado de outras psicólogas da equipe. Nessa ocasião, enfrentou divergências de posição em relação aos métodos utilizados para tanto (conseguindo, ao final, que fosse adotado um sistema de seleção em etapas - entrevista, análise de currículo, dinâmica de grupo e redação - em contraposição ao uso de testes). Muitas das atividades realizadas pelos psicólogos entrevistados eram bastante específicas e restritas à organização determinada. É o caso de trabalhos de produção de eventos, de representação institucional e de administração financeira.

A psicóloga que atuava na produção de eventos oferece um exemplo interessante. Embora tenha atuado, conforme descrito na entrevista, em tarefas que a rigor não pertencem nem à educação, nem à Psicologia, a psicóloga insiste em atribuir sentido específico à sua formação dentro de seu trabalho. Ela ingressa na ONG para atuar na organização de um prêmio educacional, e assume as atividades relacionadas à produção do evento de premiação, como contato com oficineiros, montagem de quadros e confirmação de presença dos participantes. O evento exigiu certa infraestrutura, que a ONG teve de providenciar ou conseguir junto a seus patrocinadores. Era imprescindível que fatos imprevistos não resultassem na perda do apoio de determinada entidade. Assim, uma das principais funções da psicóloga no evento era cuidar da relação entre a ONG e a entidade: ela localizou aí o sentido psi de seu trabalho.

Outras atividades realizadas por psicólogos incluíam a representação em congressos, comissões ou órgãos de representação. Nas ONGs em que a atuação política configurava parte de seu espectro de ação, era grande o número de psicólogos que, voluntariamente ou atendendo à solicitação da ONG, participavam dessa atividade. No caso de uma dirigente entrevistada, surgiu também, 
como função do psicólogo, a administração financeira (caso em que se evidenciou o gosto e o interesse da profissional pela área que passou a gerir).

A descrição de algumas atividades educacionais realizadas por psicólogos em suas organizações mereceria maior aprofundamento em função da riqueza de detalhes presente nas entrevistas, que, sem dúvida, nos ajudam a compor um quadro descritivo da forma como esses profissionais têm desenvolvido esses trabalhos em seu dia a dia. Restringimo-nos aqui em vista da natureza deste artigo. Observamos, contudo, que, no quadro das relações estabelecidas na escola e dentro das ONGs, os psicólogos identificam melhor as especificidades de seu trabalho quando podem se encontrar com seu público, seus interlocutores finais. É importante ressaltar que todos os profissionais entrevistados valorizavam sua formação, buscando os contornos de seu papel profissional mesmo quando no exercício de funções pejorativamente vistas como genéricas. Se, por um lado, essa visão em muitos casos corrobora uma concepção limitada de atuação profissional e psicológica, por outro, na medida em que o profissional busca a humanização das relações construídas por meio de seu trabalho, busca também sentidos profissionais que se contrapõem à estereotipia de suas supostas funções técnicas. É possível encontrar por essa via um escape possível às armaduras construídas naquilo mesmo que define o psicólogo enquanto tal a partir de sua formação. Se, por um lado, o modo como o profissional termina por enxergar e relacionar-se com o público que atende $^{2}$, seja por via direta ou indireta (esse é um indicador importante das concepções em jogo no exercício de suas tarefas), por outro lado, destacamos a importância em cuidarmos de uma formação profissional do psicólogo que se afaste do uso instrumental e alienado da Psicologia como técnica para aproximar-se de uma concepção de Psicologia como ciência crítica, que tenha o indivíduo por horizonte.

\section{Contratos de trabalho nas organizações não governamentais}

As relações de trabalho nas ONGs são caracterizadas pela informalidade. À exceção dos psicólogos que trabalhavam na ONG B, contratados sob as normas da CLT, nenhum outro psicólogo possuía registro em carteira de trabalho. De modo geral, os psicólogos são contratados e remunerados em função da participação em projetos. Em uma das ONGs, sequer havia remuneração para os trabalhadores da organização. Embora a psicóloga entrevistada não considerasse seu trabalho voluntário, inexistia, até o momento da entrevista, financiamento capaz de remunerar técnicos para o projeto implantado - havia apenas a perspectiva de receber através de um convênio que estava para ser celebrado com a prefeitura da cidade. Em outra ONG, o contrato de trabalho não era efetuado com o psicólogo diretamente, mas com uma empresa que o psicólogo era obrigado a abrir e a manter. Através dessa empresa, o psicólogo emitia notas fiscais de prestação de serviço, o que não eximia as psicólogas de cumprir jornada integral, de quarenta horas de trabalho semanais. Na ONG E, embora fosse oferecido em determinado momento a uma das psicólogas entrevistadas a possibilidade de obter registro funcional, ela o recusou, ante a perspectiva de redução de salário, 
devido aos descontos gerados por encargos trabalhistas e por avaliar como precário o sistema público de seguridade social. Em duas organizações, os psicólogos cumpriam jornada fixa de trabalho, em período integral. Em outra ONG, embora houvesse um acordo para que o psicólogo disponibilizasse vinte horas semanais para o trabalho, na prática, essa exigência apenas balizava a relação entre a psicóloga e sua chefia direta, porque a psicóloga deveria encontrar-se disponível permanentemente.

Duas psicólogas atuavam em mais de uma ONG simultaneamente. Nos dois casos, a situação era possível devido à flexibilidade de horário ocasionada pelo trabalho vinculado a projetos, e, por outro lado, fazia-se necessária para que complementasse sua renda mensal. Frequente, contudo, era a situação em que os psicólogos trabalhavam em mais de um projeto na mesma ONG, ao mesmo tempo - fórmula encontrada pela maioria das organizações para conseguir remunerar os técnicos de acordo com seu nível de qualificação.

No caso da ONG B, única em que os psicólogos possuíam registro de trabalho, a forma de contratação e a remuneração de seus funcionários, segundo a dirigente entrevistada, era justificada em função da necessidade da organização de manter-se coerente com os princípios defendidos e também devido ao volume de trabalho que seria exigido dos profissionais.

A despeito da informalidade presente em grande parte dos contratos de trabalho, a maioria dos psicólogos considerava sua situação estável, sendo que apenas uma entrevistada revelou alguma preocupação com o desemprego. A preocupação, no caso, surge em dois momentos: quando a psicóloga ingressa na ONG, aceitando realizar um trabalho que não correspondia às suas expectativas iniciais, e no momento de transição entre dois projetos, quando ela passa a negociar sua permanência na organização. A psicóloga, nesse caso, trabalhava na organização há cerca de um ano, aproximadamente. Em uma das entrevistas, surge a explicação para a estabilidade sentida na organização:

Tanto faz ser de uma empresa ou ser de uma ONG, se você não se der bem com a sua chefe, você está na rua..., com a diferença de que, na empresa, isso eu diria também da minha experiência, ...em empresa você tem mais concorrência. Você é uma peça, mesmo, de uma engrenagem, e se você não estiver fazendo aquilo direitinho como seu chefe quer, você simplesmente pode ser despedido a qualquer horário, a qualquer dia, do dia para a noite, e, na melhor das hipóteses, você vai ganhar o bônus, como é?, a rescisão contratual, isso não acontece em ONG. Mas você tem uma vinculação muito mais frágil, você é uma peça muito mais descartável. Você pode ser descartado e simplesmente tem um monte de gente no mercado esperando sua vaga. Agora, numa ONG, acho que não é tanto assim. As relações são muito mais pessoais, acho que os vínculos são muito mais estreitos. Até por conta dessa coisa de ser uma causa, de ser uma militância, então não é qualquer um que abraça uma causa totalmente, que compra um ideal, que compra uma causa, acho que é uma causa, mesmo, uma briga que você assume, você incorpora, mesmo, uma militância, mesmo. Então, não é muita gente que assume isso, que se compromete tanto, então, você não tem tanta concorrência. Eu, por exemplo, quando a gente estava falando de estabilidade, eu me sinto estável nesse sentido. A coordenadora, a ONG..., investiu muito em mim, conhecem muito de mim e precisam muito de mim, de certa forma. Não 
dá para eu virar, nem que eu queira sair hoje, já é muito mais amplo, as consequências, não é um vínculo empregatício meramente. Não tenho vínculo empregatício, mas eu tenho um vínculo muito maior, um vínculo pessoal, um vínculo de causa, um vínculo de projeto, mesmo.

Particularmente entre as psicólogas da ONG A, a situação de desemprego vivida no País era tomada como fator a ser considerado no momento em que se avaliava a satisfação com o próprio trabalho.

Em duas ONGs, o fato de o contrato de trabalho estar baseado em projetos temporários não significava remuneração variável, mas, ao contrário, desviava-se dinheiro de outros projetos para que se estabelecesse uma regularidade de salário para os psicólogos que nelas atuavam.

Os parâmetros para julgar a adequação do salário recebido pelo psicólogo variavam bastante de organização para organização. Em três organizações, o parâmetro era dado pelo valor comumente pago aos profissionais em outras ONGs. Nesses casos, os entrevistados julgavam seu salário maior do que o pago na média. Em duas organizações, o parâmetro era dado também pelo setor privado. Aí, o salário pago pela ONG em questão era considerado equivalente. Houve dois casos em que psicólogas trouxeram parâmetros pessoais para avaliação do próprio salário. Em um deles, o parâmetro era dado pela situação social em que a psicóloga se encontrava: casada, com carro, nível social de classe média. Para a entrevistada, o salário que recebia era considerado razoável para alguém em início de carreira, mas insuficiente para custear o conjunto de suas despesas domésticas. No outro caso, a psicóloga considerava como parte do valor de seu trabalho a entrega física e psíquica exigidas e também os custos mantidos com a atualização de seus conhecimentos na área cultural - livros, cinema, arte consumo caro e necessário para a manutenção do repertório de que fazia uso em suas atividades. Para essa psicóloga, o montante recebido não correspondia ao valor de seu trabalho. Alcança-se o ponto, então, em que a psicóloga passa a recusar ofertas de trabalho consideradas pessoalmente insatisfatórias a fim de poder criar e desenvolver trabalhos próprios.

Uma das explicações que revela a dificuldade em se atingir uma remuneração adequada em organizações não governamentais é o fato de, no Brasil, o trabalho social possuir historicamente forte vinculação com a Igreja e, em consequência, com a ideia de doação, ou, sob o novo discurso, de voluntariado. Como contraponto laico, aponta-se a busca do trabalho competente. Os discursos se entrelaçam: em uma das ONGs estudadas, empregavam-se voluntários com regularidade em um projeto específico para profissionais liberais, que prestavam serviço a crianças de baixa renda; também os dirigentes da organização (normalmente empresários) eram voluntários. Em outra ONG, voluntários se dispunham a atuar em projetos pontuais no início das atividades da organização. Nas demais organizações, que não possuíam voluntários em seus quadros, isso se devia, em um caso, a razões práticas - como não realizavam atendimento direto, precisavam apenas de trabalho especializado, no qual não se encaixam voluntários - ou a uma discordância explícita ao emprego de voluntários. Três organizações, porém, faziam largo uso do trabalho de estagiários, mal remunerados, e, em grande medida, desvinculados da ideia de aprendizado que 
deveria em princípio conter essa modalidade de formação.

Queixa comum entre os psicólogos era o excesso de trabalho, que o tornava cansativo e que dificultava ou impossibilitava a conciliação com outras atividades profissionais e pessoais, dentre elas o estudo. Apenas em uma das ONGs os psicólogos eram incentivados por sua direção a estudar, tendo por fim o crescimento pessoal e profissional. Em outra ONG, o estudo subjazia ao trabalho, de modo que os psicólogos envolvidos em pesquisa, especialmente, eram compelidos a estudar no âmbito de sua pesquisa. Especialmente nas organizações de maior porte, porém, muitos psicólogos revelavam desejo de estudar, sobretudo de fazer pós-graduação, mas a instituição dava incentivos tão somente para a realização de cursos instrumentais, como redação, línguas ou assuntos específicos, imediatamente necessários à prática cotidiana.

\section{Relações de trabalho e militância}

O trabalho assume um sentido bastante especial na vida dos psicólogos que atuam nas ONGs. Trata-se de um envolvimento profissional que excede em muito a mera contratação da força de trabalho. O compromisso assumido pelos profissionais ante os objetivos da ONG é decisivo desde o momento da seleção e da contratação do profissional, e irá permear as relações de trabalho estabelecidas durante toda a carreira do psicólogo na organização. Diante dos objetivos postos, não basta a execução de um trabalho correto, é preciso identificação com os princípios, valores e métodos apregoados e também coincidência de ação:
Eu procuro trazer sempre pessoas que possam contribuir, trazer novas competências aqui para a instituição, que possam se complementar. E checo, aí eu entrevisto também, aí eu troco ideias com a chefia direta, aí eu dou uma checada mais em caráter, também, atitude, valores, principalmente. Eu acho superimportante que os valores da pessoa batam, sejam os mesmos ou muito parecidos com os valores da instituição.... Acho que valores de respeito, de solidariedade, de acreditar na causa, de ter um compromisso com a causa, não ter preconceito com o empresariado, por exemplo. Tem muita gente de esquerda que tem um pouco de ranço, e aí não vai dar certo, porque nós somos dirigidos por empresários; precisa ter um respeito mínimo, respeito à diversidade, enfim. Hoje em dia, está muito na moda as pessoas quererem trabalhar no terceiro setor, porque tem causas boas, enfim, mas nem todo mundo pratica, também.

Em todas as entrevistas, os psicólogos revelavam essa identidade de valores. Dessa forma, o contrato de trabalho se torna, necessariamente, um compromisso assumido frente aos ideais defendidos pela ONG. O psicólogo se transforma em um militante, ou, como expressa uma das entrevistadas, é obrigado a vestir a camisa da organização:

Então, exige uma dedicação, de meio que "vestir uma camisa".... Até tem uma coisa que é engraçada, há pouco tempo atrás, na verdade, um desconhecido: "O que você faz?", "Ah, eu trabalho numa ONG". A pessoa virou assim: "Mas qual a causa que sua ONG defende?" Eu achei muito engraçado, na hora eu dei muita risada, esse jeito de falar "a causa". Na verdade, é um pouco isso, as ONGs defendem uma causa. Nossa causa é a causa $x$, mas, porque eu acho interessante, não só pelo termo ser engraçado, mas porque acho que isso reflete exatamente o que é trabalhar numa ONG, você ter uma causa. Então hoje, a dimensão da ONG na minha vida não é só meu trabalho, que eu vou lá e faço e volto para casa.... É a coisa da causa. Por isso eu 
falei que me pegou muito essa frase que essa pessoa falou. Não é só porque é engraçado, fala muito do que é trabalhar numa ONG. É vestir a camisa, é o que eu chamei de vestir a camisa, é você ser aquilo. Não é que você trabalha com aquilo, trabalha naquele lugar. Você é. Eu sou a ONG. E às vezes me incomoda. Dá um puta orgulho, você vê que eu falo mais bem do que mal, porque eu acho que se não fosse assim, não seria.

Os limites entre o trabalho e a vida pessoal tornam-se, em razão dessa dedicação, mais estreitos, uma vez que o trabalho passa a exigir maior envolvimento do psicólogo. $\mathrm{Na}$ experiência de um dos psicólogos, não se trata mais da dificuldade em estabelecer limites pessoais ante a imposição dos valores da ONG, mas de tornar seu trabalho parte de suas reflexões, e vice-versa:

E, assim, muitas vezes, eu fiz um papel eminentemente político, de discutir. Muitas vezes eu me perguntei: "Eu estou sendo um psicólogo, aqui, ou estou sendo um militante?" E, ultimamente, eu tenho pensado: "bom, mas o psicólogo é um militante. Mas que militância é essa? Especificamente psicológica? Existe uma militância especificamente psicológica, ou não, que se serve de teorias psicológicas e técnicas psicológicas? Uma escuta psicanalítica, psicológica? Como é que é isso? Quais são os limites? Qual é a ética envolvida nisso?" Ter uma posição mais ativa... não sei. É legal. É uma responsabilidade, traz muita dor de cabeça, te faz trabalhar muito. O trabalho passa a ocupar uma parte muito grande da sua vida. Eu me pego pensando nisso, trabalhando espontaneamente no domingo.

O sentido dessa invasão do lazer torna-se outro, a despeito da sensação de perda com a qual se mostra, e que, possivelmente advenha da própria inadequação da atividade militante à lógica de mercado, de venda do trabalho (também aqui repetitivo e estafante): cenário onde o psicólogo que busca a praxis termina por sentir-se lesado, como que trabalhando gratuitamente - o que, por si, contradiz o discurso de que o trabalho social seria igualmente vantajoso.

Para outra psicóloga, a própria flexibilidade de horário termina por relacionar-se ao compromisso assumido, de um modo que a dedicação exigida resulta em pressões que implicam perdas na esfera pessoal. O trabalho vai importar, dessa maneira, na opção de assumir ou não relacionamentos afetivos, de ter filhos, na relação com os amigos, e mesmo na possibilidade de dedicar-se à sua religião.

As relações internas estabelecidas no interior das ONGs são bastante diferentes em cada uma delas. Em todas elas encontramos uma organização interna hierárquica, algumas mais rígidas, outras menos, com maior ou menor concentração de poderes. Em todos os casos, porém, as concepções e as características pessoais dos dirigentes da organização exerciam grande influência no modo como o trabalho seria organizado dentro da ONG. Nas duas organizações onde os psicólogos mais se dispuseram a falar sobre o assunto, encontramos situações opostas. Em uma delas, o dirigente trabalhava para conseguir maior participação e debate entre os funcionários, e, na outra, a psicóloga se deparava com o excesso de controle e centralização exercidos pela coordenação. Nesse caso, os coordenadores e fundadores da organização eram considerados, sob certo aspecto, donos da ONG; a centralização posta por eles como sistema de trabalho irá conferir-lhes maior poder de decisão e grande controle sobre as atividades desenvolvidas. No primeiro caso mencionado, ao contrário, a construção da democracia no grupo se coloca para o dirigente como um ideal, que 
envolve, contudo, uma série de dificuldades, incluindo os interesses de cada profissional. É um trabalho difícil, mas que o psicólogo encontra grande satisfação em realizar:

Atualmente, a gente está vivendo uma crise de relacionamento, na equipe de trabalho, de esclarecimentos, de função, e especialmente de poderes... Não dá para extinguir isso, então a gente está passando por uma recontratação do trabalho entre nós. Tem uma série de dificuldades, principalmente porque a gente não quer trabalhar num modelo gerencial. $A$ gente pretende, também entre nós, construir uma gestão coletiva do trabalho, porque a gente acredita que só assim a gente vai conseguir construir isso com os meninos, falar sobre isso com os funcionários. Então, apesar de todos os problemas e pepinos, eu sinto grande satisfação, porque eu sinto que é um trabalho que a gente está criando. A gente tem bastante terreno para experimentar, para ensaiar, para errar e para construir conhecimento em cima disso. Isso é bem legal, é bem interessante.

O sentido social ou político da ação realizada fará parte da recompensa alcançada pelo psicólogo em seu trabalho. Embora sinais de descontentamento surjam ao longo das entrevistas, as insatisfações, na maioria dos casos, eram minimizadas em virtude do benefício maior a ser atingido, mesmo que o psicólogo não participasse diretamente dos resultados concretos desse trabalho. Em graus diferentes - alguns casos como mera satisfação pelo trabalho bem feito - todos os psicólogos se declararam contentes com o trabalho que realizam. Parte da motivação e do sentido atribuído por eles ao seu trabalho está relacionada aos ideais que norteiam a atuação da ONG. Em todas elas, o trabalho dos psicólogos portará para eles um sentido coletivo, de melhoria da educação pública, de acesso à cultura e à saúde, de promoção de melhores condições de trabalho, de redução da miséria ou de melhor distribuição das riquezas no País, pontos que se transformam, assim, em componentes de satisfação pessoal e profissional.

\section{Considerações finais}

Embora os psicólogos que participaram da pesquisa possuíssem grau de qualificação elevado, suas possibilidades de qualificação e manutenção dos estudos contraditoriamente (sobretudo tendo em vista atuarem na área educacional) se reduziam na medida em que avançavam na carreira dentro das ONGs. O volume de trabalho e o caráter muitas vezes repetitivo de suas tarefas acabavam se tornando um obstáculo à reflexão.

Os psicólogos, de modo geral, conseguiam construir uma carreira dentro das organizações, permanecendo ali durante vários anos, e tendiam a perceber seu vínculo como estável, ainda que, na grande maioria dos casos, inexista um vínculo empregatício devidamente formalizado. Essa percepção, como os próprios psicólogos ressaltam, está relacionada a dois fatores principais: o grau de especialização que atingem com seu trabalho ao longo dos anos, por um lado, e, de outro, ao conjunto de valores que, característica intrínseca ao trabalho nas ONGs, necessariamente devem manter em relação à organização. Aquilo que alguns psicólogos descrevem como uma característica militante de seu trabalho acaba, no entanto, sendo também qualificável como um vestir a camisa, algo de todo oposto à ideia de militância. Afinal, camisa é um objeto descartável, passível de troca fácil, e que, em geral, está associada à dedicação de um funcionário em uma empresa, é irracional e assemelhada à adesão de um jogador ou torcedor a um time de futebol - relacionamento bastante diverso daquele esperado entre pessoas espontaneamente 
voltadas para determinada causa. Em meio à propositada confusão entre público e privado que comparece nos discursos correntes, verificamos ser comum no setor o fato de os valores pessoais do profissional acabarem também eles se tornando moeda de troca no mercado não governamental. Esse tipo de vinculação, no entanto, mostra-se bastante adequado à redução dos custos da atividade social que se espera obter por meio das ONGs, através de uma remuneração do trabalho por produção, e não por tempo de dedicação e serviço.

Por outro lado, o caráter coletivo dos trabalhos realizados nas organizações não governamentais acaba, em si, constituindo fonte de satisfação para os profissionais envolvidos, pois eles sentem que seu trabalho é relevante e necessário - ainda que isso, em muitos casos, signifique uma carga de trabalho julgada excessiva e desviada para funções pouco nobres. Tais casos, bastante frequentes, relacionam-se à burocracia que cerca suas atividades, a qual comparece aí não por um acaso, mas como parte integrante do aparato de controle que cerca as organizações não governamentais.

É importante lembrar que o crescimento do dito terceiro setor não é exatamente um fenômeno novo no Brasil; organizações externas ao aparato governamental em ação na área social existem desde os primórdios da história brasileira. A novidade do momento atual, que Edson Passetti (2000) denomina nova filantropia, consiste, na verdade, em um ciclo assistencial de subvenção do Estado a entidades e empresas privadas por meio do que estas deixam de recolher aos cofres públicos, via isenção de impostos, em troca da prestação de serviços. Em outras palavras, o grande financiador do setor não governamental permanece sendo o governo, ainda que este não atue mais diretamente no planejamento e na execução da atividade social. Não há, portanto, uma Terceira Via para a área educacional (como apregoam as teorias sociológicas que a defendem como alternativa política pós Guerra Fria), mas uma terceirização dos serviços sociais com características próprias, adaptadas ao momento econômico atual (Dadico, 2006). Assim, muitas das dificuldades que os psicólogos percebem ao buscarem desenvolver os projetos que nutrem a partir de suas reflexões e de uma Psicologia comprometida com uma visão emancipatória de educação esbarram justamente nas dificuldades impostas pela burocracia no acesso aos recursos públicos, sejam estes solicitados diretamente nos balcões estatais, via empresas privadas, seja junto a grandes organizações nacionais e internacionais. Existe um determinado modelo de projeto que dá chances maiores de obter acesso a recursos financeiros, e que, obviamente, comporta também determinado modo de se atuar socialmente.

Os psicólogos que se mostravam mais atentos a essas questões buscavam continuamente desenvolver estratégias para escapar aos controles que lhes eram impostos, embora nem sempre fossem bem sucedidos em sua tarefa. Verificamos que tendiam a exercer suas atividades de modo mais próximo a suas convicções pessoais nas ONGs de menor porte, aquelas que justamente acabam se caracterizando por uma quantidade menor de recursos disponíveis, menor raio de ação e menor capacidade de atuação e de negociação. Nas ONGs maiores, a estruturação hierárquica interna e a própria lógica do mercado na disputa por recursos acabava por gerar limites difíceis de serem superados individualmente pelos profissionais. É importante ter em vista, então, que os adjetivos espontaneidade, pró-atividade, 
liberdade e responsabilidade, associados ao terceiro setor não qualificam bem o trabalho aí oferecido. Os psicólogos que desejam atuar nas áreas social, educacional ou diretamente em organizações não governamentais precisam ter em mente as peculiaridades e os limites que caracterizam o trabalho no setor não governamental a fim de poder encontrar brechas que lhes permitam o exercício da práxis. 


\section{Luciana Dadico*}

Mestre, bolsista de doutorado em Psicologia Escolar e do Desenvolvimento Humano - CNPq. Instituto de Psicologia da Universidade de São Paulo, São Paulo, SP - Brasil.

\section{Marilene Proença Rebello de Souza}

Doutora em Psicologia Escolar, professora assistente do Instituto de Psicologia da Universidade de São Paulo, São Paulo, SP - Brasil.

E-mail: mprdsouz@usp.br

*Endereço para envio de correspondência:

Departamento de Psicologia Escolar, da Aprendizagem e do Desenvolvimento do Instituto de Psicologia da USP PSA. Av. Prof. Mello Moraes, 1721 - Cidade Universitária - São Paulo, SP - Brasil - CEP: 05508-030.

E-mail: ludadico@ig.com.br

Recebido 27/1/2009, 1ㅍ- Reformulação 24/7/2009, Aprovado 10/8/2009.

Arantes, P. E. (2000). Esquerda e direita no espelho das ONGs. Cadernos ABONG Ongs: identidades e desafios atuais, (27), 47-57.

Conselho Federal de Psicologia. (2003). Relatório final da pesquisa sobre o perfil do psicólogo brasileiro. Recuperado em 21 de junho de 2003, de http://www.pol.org.br/atualidades/ materias.cfm?id_area $=300$

Dadico, L. (2003). Atuação do psicólogo em organizações não-governamentais na área da educação. Dissertação de Mestrado, Instituto de Psicologia, Universidade de São Paulo, São Paulo. Recuperado em 11 de janeiro de 2008, de http://www.teses.usp.br/teses/disponiveis/47/47131/tde23112004-140530/

Dadico, L. (2006). Terceira via, ideologia e educação. In C. B. Angelucci \& L. S. Viégas (Orgs.), Políticas públicas em educação: uma análise crítica a partir da psicologia escolar (pp. 25-46). São Paulo: Casa do Psicólogo.

Instituto Brasileiro de Geografia e Estatística. (2005). As fundações privadas e associações sem fins lucrativos no Brasil. Rio de Janeiro: Autor.

Instituto Brasileiro de Geografia e Estatística. (2007). As entidades de assistência social privadas sem fins lucrativos no Brasil. Rio de Janeiro: Autor

Macedo, K. B. (2008). O trabalho dos psicólogos nas empresas públicas, privadas e do terceiro setor. In Anais do III Congresso Brasileiro de Psicologia Organizacional e do Trabalho,
Florianópolis, SC. Recuperado em 21 de julho de 2009, de http://www.sbpot.org.br/iiicbpot/programacao/mr12.html

Oliveira, P. S. (Org.). (1998). Metodologia das ciências humanas. São Paulo: Hucitec.

Passetti, E. (2000). Crianças carentes e políticas públicas. In M. D. Priore (Org.), História das crianças no Brasil (2a ed.). São Paulo: Contexto.

Queiróz, M. I. P. (1983). Variações sobre a técnica de gravador no registro da informação viva. São Paulo: CERU/FFLCH-USP.

Rockwell, E. (1987). Reflexiones sobre el processo etnográfico (1982-1985). México: DIE-CINVESTAV/IPN. (Trabalho não publicado)

Santos, N. C. R. A. (2003). A formação dos psicólogos na década de 1990: uma leitura frankfurtiana. In M. Nenevé, M. Proença \& R. Ribeiro (Orgs.), Psicologia e saúde na Amazônia: pesquisa e realidade brasileira (pp. 39-63). São Paulo: Casa do Psicólogo.

Souza, M. P. R. (2000). A queixa escolar na formação de psicólogos: desafios e perspectivas. In E. Tanamachi, M. Proença, \& M. Lopes da Rocha, Psicologia e educação: desafios teórico-práticos (pp. 105-141). São Paulo: Casa do Psicólogo. 